\title{
Developing New Technology Acceptance Model With Multi-Criteria Decision Technique: An Implementation Study
}

\author{
Murat Oturakci ${ }^{1}$ \\ ${ }^{1}$ Industrial Engineering Department, Faculty of Engineering, Adana Science and Technology University, Adana, \\ Turkey \\ Correspondence: Murat Oturakci, Industrial Engineering Department, Faculty of Engineering, Adana Science \\ and Technology University, Adana, Turkey. E-mail: moturakci@adanabtu.edu.tr
}

Received: August 15, 2018

Accepted: October 14, 2018 Online Published: October 17, 2018

doi:10.5539/emr.v7n2p43

URL: http://doi.org/10.5539/emr.v7n2p43

\begin{abstract}
This study aims to develop and implement a new Technology Acceptance Model (TAM) to verify and explain users' acceptance of SAP software. The structural equation model (SEM) technique is used with the AMOS program for the adoption process. General structural model, which includes Experience, Voluntariness, Perceived Enjoyment, Perceptions of External Control, Computer Self Efficacy, Output Quality and Job Relevance, is developed with Analytical Hierarchy Method (AHP) and Pareto Analysis by deciding variables from previously original developed models which are called TAM1, TAM2 and TAM3. New TAM is tested to a sample of 384 SAP users in a company that serves in metal production. Results illustrates that new TAM is an appropriate tool to explain and understand users' acceptance of SAP besides of being flexible and easily implemented. SAP users' job relevance and their perceptions of external control are the most important variables that affect perceived usefulness and perceived ease of use in the model.
\end{abstract}

Keywords: technology acceptance model, SAP users, analytical hierarchy process, pareto analysis

\section{Introduction}

In recent years, advancement of technology force companies to perform all their business functions electronically. From performing daily tasks to enhancement of businesses; organizations use several applications in order to survive in a digital world. Thus, technology transfer and technology adoption terms become significantly valuable for both practitioners and researchers since appropriate applications and implementations are one of the key success factors. Appropriate adaptation of technology depends on faultless execution of technology transfer since technology transfer is the combination of sharing skills, knowledge, technologies among institutions. In transfer process, adaptation of technology may vary in different levels. Hence, existing theories and models of acceptance of new technology helps to create and demonstrate an appropriate theoretical framework (Lala, 2014).

TAM is an information systems theory that has an ability to reveal to make predictions about acceptance (Lala, 2014). Technology acceptance studies have been started to study by Fred D Davis (1985) to provide determinants of computer acceptance by taking Theory of Reasoned Action (TRA) as a reference from Fishbein and Ajzen (1975). After building of a conceptual model for TAM, final version of TAM has been formed by Venkatesh and Davis (1996). In TAM, it is assumed that information system acceptance is determined by Perceived Usefulness and Perceived Ease of Use which can be inferred that those two variables are the only constant variables in every TAM. Over the years, TAM 2 and TAM3 have been developed by the original authors and variables of those three models have been presented in Table 1. 
Table 1. Original TAM variables

\begin{tabular}{lll}
\hline $\begin{array}{l}\text { TAM1 } \\
\text { (Venkatesh \& Davis, 1996) }\end{array}$ & $\begin{array}{l}\text { TAM2 } \\
\text { (Venkatesh \& Davis, 2000) }\end{array}$ & $\begin{array}{l}\text { TAM3 } \\
\text { (Venkatesh, 2000) }\end{array}$ \\
\hline External Variables & Subjective Norms & Computer Self-Efficacy \\
Perceived Usefulness* & Image & Perceptions of External Control \\
Perceived Ease of Use* & Job Relevance & Pemputer Playfulness \\
Behavioral Intention & Output Quality & Objective Usability \\
Actual System Use & Result Demonstrability & Perceived Usefulness* \\
& Experience & Perceived Ease of Use* \\
& Voluntariness & Behavioral Intention to Use \\
& Perceived Usefulness* & \\
& Perceived Ease of Use* & \\
& Intention to Use & \\
& Usage Behavior & \\
\hline
\end{tabular}

Besides of models which are developed by the same authors (TAM1, TAM2, and TAM3) who developed the first model; there are many studies in literature that grounds on those models with differentiation of variables to make predictions about technology acceptance.

Heijden (2004), performed to obtain valid results for user acceptance of hedonic information systems by using TAM. By building SEM among four main parameters such as perceived ease of use, perceived usefulness and perceived enjoyment as an independent; intention to use as a dependent variable. As a result; perceived ease of use and perceived enjoyment were a strong predictor than perceived usefulness for hedonic information systems. $\mathrm{Wu}$ and Wang (2005), presented an integrated TAM with innovation diffusion theory to determine user mobile commerce acceptance by building SEM. Adding perceived risk, compatibility and cost variables besides perceived usefulness and perceived ease of use as an independent variable; study stated that integration of compatibility variable became the most important determinant for behavioral intention to use for mobile commerce acceptance. S. Y. Park (2009), constructed a modified TAM to understand users' acceptance of e-learning. By constructing a SEM, authors concluded that e-learning self-efficacy and subjective norm were the most important variables in influencing behavioral intention to use e-learning. Alharbi and Drew (2014) presented a modified TAM to assist public universities in Saudi Arabia to predict user acceptance of learning management systems for behavioral intention. Implementing original TAM model with the support of job relevance, lack of availability and usage experience variables as external; all hypotheses in study were proven to have positive correlations that are statistically significant. E. Park and Kim (2014) investigated user perceptions and attitude toward mobile cloud computing services with TAM. SEM analysis used to test for modified model. Perceived mobility, perceived usefulness, perceived connectedness, perceived security, system quality and satisfaction were selected as independent variables to find out which contributed more on attitude and intention to use mobile cloud services. Persico, Manca, and Pozzi (2014) evaluated innovative potential of e-learning systems by adapting TAM. This study revealed three dimensional model for the evaluation for e-learning systems as users; course development phases and system components as dependent variables. This three dimensional approach proved that several sources of data that could be mapped with different aspects. Rauniar et al. (2014) evaluated actual use of social media tools with a revised TAM by using perceived ease of use, critical mass, capability, perceived playfulness, trustworthiness as independent variables. Study enhanced TAM framework to understand of social media users' attitudes toward usage. Samaradiwakara and Gunawardena (2014) aimed to develop well improved TAM by comparing existing models in literature. Study compared all possible models in literature with their explained variance $\left(\mathrm{R}^{2}\right)$. After analyzing nine different technology acceptance based model, authors stated that Unified Theory of Acceptance and Use of Technology Model (UTAUT) is the well-developed model since it has the highest explanatory power. Wallace and Sheetz (2014) proposed and tested a TAM based model of software measure use. Authors tested a model which attempted to explain and predict the use of software measures. "Measure use" presented as dependent variable in the study 
and it was explained by perceived usefulness mostly. Briz-Ponce and Garcia-Penalvo (2015) aimed to design and implement a TAM for explaining the acceptance of mobile technology and "apps" in Medical Education. Recommendation and self-efficacy were found as key determinants for the Behavioral intention to use the new technology in the study. Fathema, Shannon, and Ross (2015) investigated factors that affect faculty members' learning management system usage behavior with an expanded TAM with using SEM. Authors confirmed that perceived self-efficacy, systems quality and facilitating conditions have the most significant influence on the use of leaning management systems by users. Rondan-Cataluña, Arenas-Gaitán, and Ramírez-Correa (2015) provided an enhanced examination of TAM and performed a comparison of partial least squares for all possible models. Study concluded that Unified Theory of Acceptance and Use of Technology Model 2 had a better explanatory power among acceptance models in the sample of mobile internet users. Abdullah and Ward (2016) developed a general extended TAM for e-learning (GETAMEL) to identify most commonly used external factors. Authors concluded that self- efficacy, subjective norm, enjoyment, computer anxiety and experience are the most commonly used external factors of TAM. With the validation of GETAMEL; self-efficacy was found as the best predictor followed by enjoyment. Kim, Lee, Mun, and Johnson (2016) examined the suitability of TAM for explaining consumer adoption of smart in store technology with using SEM. Study showed that perceived enjoyment is more important than usefulness to create consumers' favorable attitude towards smart in store technology. Serçemeli and Kurnaz (2016) aimed to investigate the reasons of auditors' usage of information technology with the help of TAM. According to the results of the study, perceived usefulness and intention tendencies of the use of information technologies defined as the most important factors. Marakarkandy, Yajnik, and Dasgupta (2017) aimed to determine most significant factors for adoption of internet banking among subjective norm, image, banks initiative, self-efficacy, internet usage efficacy, trust, perceived risk, trialability and government support. Brandon-Jones and Kauppi (2018) examined the predictors of TAM within e-procurement. Processing, content, usability, training and professionalism were selected as external variables for the TAM. According to the SEM results; processing, usability, and professionalism were found as the most significant factors for employees' e-procurement acceptance. To and Tang (2018) extended a TAM with the combination of subjective norms and perceived relevance to explore the antecedents of students' intention to participate in computer based course evaluation. With using analysis of SEM, subjective norms had a significant effect on perceived relevance as well as perceived usefulness and subjective norm had a significant effect on students' intention to participate in computer-based course evaluation.

In previously conducted studies, technology acceptance models were developed or enhanced by adding new variables with using other studies' variables. Developing a TAM for any case by determining its variables from previously conducted studies can verify models which are related with each other but it creates boundedness and rigidness among studies since those variables will only have a chance to be verified in later steps of those studies with the help of SEM which illustrates that previous studies models' were not constructed with an analytical approach. If the selection processes of variables that will be included in TAM are selected with an analytical method, it will help model to be more flexible besides of being more accurate since some of the variables will be excluded before further analysis. Thus, this study attempts to fill the gap of the literature by using Analytical Hierarchy Process (AHP) and Pareto Analysis for a selection method which illustrates the original and significant part of the study besides of creating new and flexible TAM.

From this point of view, the aim of this study is to develop, implement and verify new TAM to measure and explain the users' acceptance of SAP software by selecting its variables from previously original developed models which are called TAM1, TAM2 and TAM3. Selection of variables are determined with Analytical Hierarchy Process (AHP) which is a multi-criteria decision making technique with the help of Pareto analysis to decide which variables will be included to employ SEM in this study.

Study consists of two major parts. In the first part of the study, all independent variables from original TAM studies (Fred D Davis, 1989; F. D. Davis, Bagozzi, \& Warshaw, 1989; Venkatesh, 2000; Venkatesh \& Davis, 1996, 2000) are compared with AHP technique and Pareto Analysis to decide which variables will be included to the model. Second part of the study includes SEM illustration and all possible calculations to verify the new TAM for the users' acceptance of SAP software.

\section{Material and Method}

\subsection{Data Characteristics and Measurements}

In this study, which significantly attempts to develop and verify a new TAM for users' acceptance of SAP software in a production company, it has been aimed to reach over 500 employees but 384 of them were seen to be eligible to continue to study. Questions have been compiled from the literature to conduct the further analysis. 
All items modified to fit the context of this study. TAM1 questions are compiled from the study of Venkatesh and Davis (1996) while TAM2 and TAM3 questions are gathered from Venkatesh and Davis (2000) and Venkatesh (2000) respectively. Before any analysis of the study, admissibility of the questionnaire is assessed and Cronbach's Alpha coefficient has been calculated over 0.80 for each parameter. SEM is employed with the AMOS program to explain the new research model and adoption process.

Study has been conducted with SAP users in all departments of a production company. Company characteristics are given in Table 2 .

Table 2. Company characteristics

\begin{tabular}{ll}
\hline Company Industry & Metal Production \\
\hline Firm Age & 32 \\
Firm Size (White Collar) & 500 \\
Sample Size & 384 \\
Respondent Ratio & $76.80 \%$ \\
Gender & Male: 286 \\
& Female: 98 \\
Age Distribution & Under 25: 16 \\
& Between 25-34: 180 \\
Education Level & Over 35: 188 \\
& University Degree and More: 239 \\
Experience & University Degree and Less: 145 \\
& Under 5 Years: 101 \\
\hline
\end{tabular}

\subsection{Analytical Hierarchy Process (AHP)}

AHP method is developed by Thomas Saaty as a multi criteria decision method (Saaty, 1980). AHP is one of the most widely used methods among decision-reaching techniques. In AHP, first, problem is needed to be clearly defined. Afterwards, target, main criteria and sub-criteria are required to be determined to create interactions between criteria and alternatives in order to build a hierarchical structure formulation. Binary comparisons are made by taking reference of a scale which is presented in Table 3 (Saaty, 1980).

Table 3. AHP comparison table (Saaty, 1980)

\begin{tabular}{ll}
\hline Importance Intensity & Description \\
\hline 1 & Equal importance \\
3 & Moderate importance of one over another \\
5 & Strong importance of one over another \\
7 & Very strong importance of one over another \\
9 & Extreme importance of one over another \\
$2,4,6,8$ & Intermediate values \\
Reciprocals & Reciprocals for inverse comparison \\
\hline
\end{tabular}

For each formed matrix, consistency ratio must be calculated which is defined by Saaty as consistency index/random index while random index is based on the number of criteria (n) and consistency index is formulated by deducting $\mathrm{n}$ from the largest eigenvalue of matrix $\left(\lambda_{\max }\right)$ and divided by $\mathrm{n}-1$. Consistency ratio should be less or equal to 0.10 , otherwise compassion matrix must be revised. AHP combine all individual 
judgements for the final weights according to the geometric rule of Saaty (1989). According to the final weights, alternatives become ready for reciprocal interpretations. The complexity of AHP algorithms' calculation can be solved by many programs such as Super decision or Expert Choice. However, calculations are made in MS Excel for this study.

\section{Findings}

\subsection{AHP Findings}

In order to decide which independent variables are needed to be included in research model; AHP method is used and results are given at below. All possible variables from original studies are presented to 5 different decision makers who are working as top management level in the company to make the binary comparisons among variables. Variables of "Perceived Usefulness and Perceived Ease of Use" have not been added for binary comparisons since those variables are the two constant variables in every study. Also "Intention to Use" is selected as dependent variable since user intentions are purposed to predict in this study. According to the comparisons by decision makers; results are shown in Table 4 .

Table 4. AHP results

\begin{tabular}{lll}
\hline Parameters & Weights* & Cumulative Sum of Weights \\
\hline Experience (EX) & $\mathbf{0 . 1 6 6 3}$ & $\mathbf{1 6 . 6 3 \%}$ \\
Voluntariness (VL) & $\mathbf{0 . 1 5 7 7}$ & $\mathbf{3 2 . 4 0 \%}$ \\
Perceived Enjoyment (PE) & $\mathbf{0 . 1 1 5 4}$ & $\mathbf{4 3 . 9 4 \%}$ \\
Perceptions of External Control (PEC) & $\mathbf{0 . 1 1 4 6}$ & $\mathbf{5 5 . 4 0 \%}$ \\
Computer Self Efficacy (CSE) & $\mathbf{0 . 0 9 9 4}$ & $\mathbf{6 5 . 3 4 \%}$ \\
Output Quality (OQ) & $\mathbf{0 . 0 9 1 3}$ & $\mathbf{7 4 . 4 7 \%}$ \\
Job Relevance (JR) & $\mathbf{0 . 0 7 3 8}$ & $\mathbf{8 1 . 8 5 \%}$ \\
Computer Playfulness (CP) & 0.0409 & $85.94 \%$ \\
Objective Usability (OU) & 0.0384 & $89.78 \%$ \\
Computer Anxiety (CA) & 0.0351 & $93.29 \%$ \\
Result Demonstrability (RD) & 0.0306 & $96.35 \%$ \\
Image (IM) & 0.0206 & $98.42 \%$ \\
Subjective Norms (SN) & 0.0158 & $100.00 \%$ \\
\hline
\end{tabular}

*Weights are calculated as the average of 5 different decision-makers' binary comparisons.

As it is illustrated in Table $\mathrm{X}$, total of 13 independent variables are asked to make comparisons to decision makers to make binary comparisons. According to the comparisons, average weight of each variable is calculated (calculation steps have been given in section 2). Experience and voluntariness are the most significant variables that need to be considered followed by perceived enjoyment and perceptions of external control and so on. When the descending order of weights of variables is examined, it is quite hard to decide which variables are needed to put into a considered TAM. To make this decision apart from being subjective in addition to avoid complicacy, number of variables are needed to be reduced to represent the model. To reduce the number of independent variables, Pareto Analysis is exercised since it is used for separating criteria according to 80-20 rule. Thus, cumulative sum of weights are calculated and variables of Experience, Voluntariness, Perceived Enjoyment, Perceptions of External Control, Computer Self Efficacy, Output Quality and Job Relevance are decided to create the research TAM. Pareto chart is shown in Figure 1. 


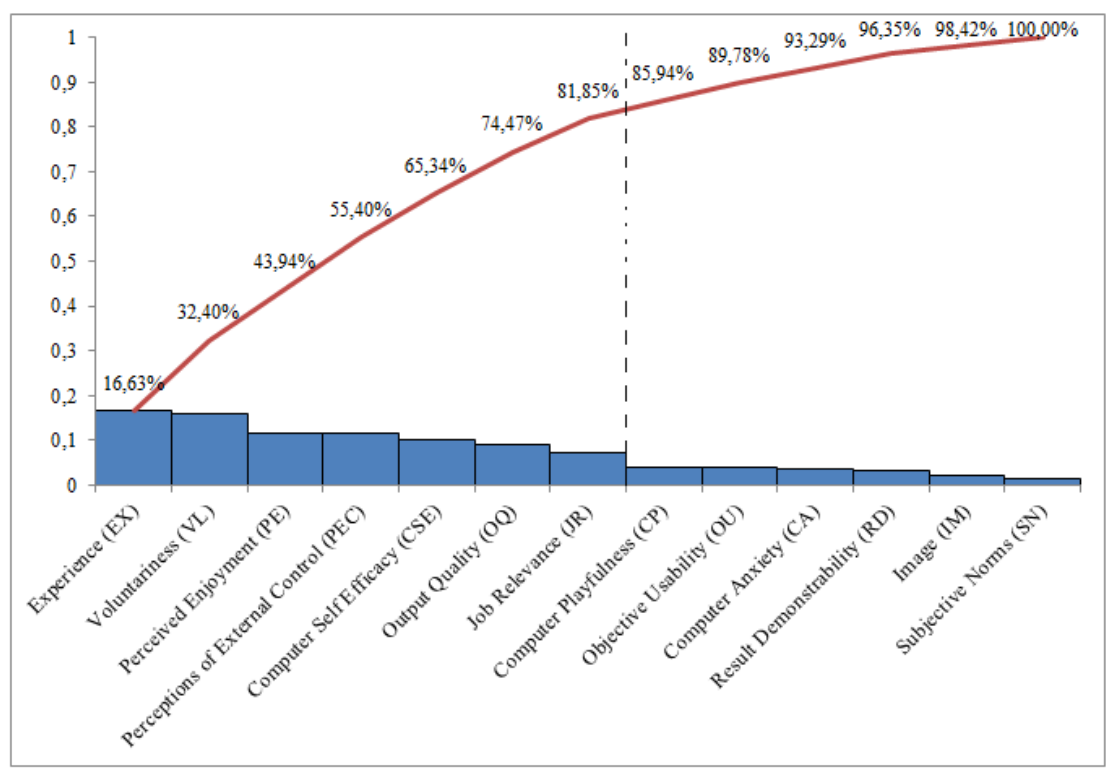

Figure 1. Pareto chart

\subsection{Research Model and SEM Findings}

Following the selection of variables with an AHP by decision makers; research model is developed and SEM structure is illustrated in Figure 2. In research model, Experience, Voluntariness, Perceived Enjoyment, Perceptions of External Control, Computer Self Efficacy, Output Quality and Job Relevance are selected as independent variables to measure and explain the users' acceptance of SAP software According to the model, six main hypotheses are shown on model and defined as follows;

H1: There is a significant relationship between job relevance (JR) and perceived usefulness (PU)

$\mathrm{H} 2$ : There is a significant relationship between output quality (OU) and perceived usefulness (PU)

$\mathrm{H} 3$ : There is a significant relationship between perceived enjoyment $(\mathrm{PE})$ and perceived ease of use (PEOU)

H4: There is a significant relationship between perceptions of external control (PEC) and perceived ease of use (PEOU)

H5: There is a significant relationship between computer self-efficacy (CSE) and perceived ease of use (PEOU)

H6: There is a significant relationship between experience (EX) and perceived usefulness (PU)

H7: There is a significant relationship between experience (EX) and intention to use (IU)

H8: There is a significant relationship between voluntariness (VL) and perceived usefulness (PU)

H9: There is a significant relationship between voluntariness (VL) and intention to use (IU)

H10: There is a significant relationship between perceived ease of use (PEOU) and perceived usefulness (PU)

H11: There is a significant relationship between perceived ease of use (PEOU) and intention to use (IU)

H12: There is a significant relationship between perceived usefulness (PU) and intention to use (IU)

Apart from main hypotheses, strongest predictors of user intention; correlation among independent variables are examined with testing their significance levels to test research model thoroughly. Before testing hypotheses, fit indices are examined and presented in Table 5 for the research model in order to reveal how correct theoretical model fits the observed data that have been collected. 
Table 5. Fit Indices of research model

\begin{tabular}{llll}
\hline Fit Index & Research Model & Recommended value & Source \\
\hline CMIN/df & 1.042 & $<5.00$ & Shin and Shin (2011) \\
GFI & 0.998 & $>0.90$ & Bagozzi and Yi (1988) \\
AGFI & 0.970 & $>0.90$ & Fornell and Larcker (1981) \\
RMSEA & 0.010 & $<0.06$ & Jöreskog and Sörbom (1996) \\
NFI & 0.995 & $>0.90$ & Bentler and Bonett (1980) \\
CFI & 1.000 & $>0.90$ & Bentler and Bonett (1980) \\
IFI & 1.000 & $>0.90$ & Bentler and Bonett (1980) \\
\hline
\end{tabular}

Table 5 presents that, all model fit indices satisfy recommended values according to literature values. Hence, research model is considered that it has a good fit with the data collected.

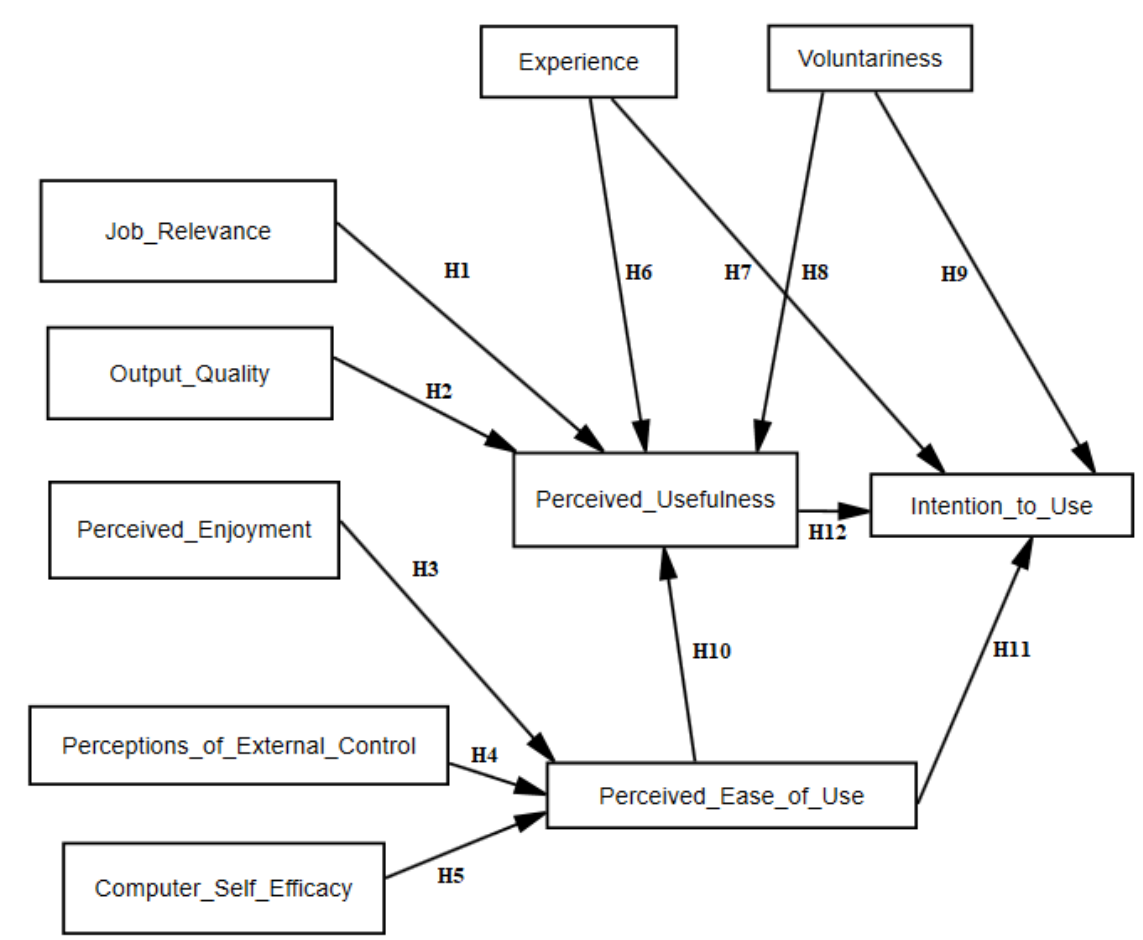

Figure 2. Research model

Hypothesis tests results are presented in Table 6. According to the test results ten out of twelve main hypotheses are supported as relationship between two variables are significant under different significance levels. As it is mentioned in the earlier parts of this study; JR, OU, EX and VL are selected from TAM3 and it has been found that those variables are in a significant relationship with PU and IU respectively which coincide with the study of Venkatesh (2000) where TAM3 is presented. Additionally, PEC and CSE are found in a significant relationship with PEOU, which is a parallel result with the study of Venkatesh and Davis (2000) where the TAM2 is proposed. Also significant relationship with PEOU and PU; PEOU and IU; PU and IU presents the similar results with all three original models (Venkatesh, 2000; Venkatesh \& Davis, 1996, 2000). 
Table 6. Test results

\begin{tabular}{lll}
\hline Hypotheses & Supported & Explanation \\
\hline H1: (JR -PU) & Yes* & Significant positive relationship \\
H2: (OU- PU) & Yes* & Significant positive relationship \\
H3: (PE-PEOU) & No & -- \\
H4: (PEC-PEOU) & Yes* & Significant positive relationship \\
H5: (CSE-PEOU) & Yes** & Significant negative relationship \\
H6: (EX-PU) & Yes** & Significant positive relationship \\
H7: (EX-IU) & No & -- \\
H8: $($ VL-PU) & Yes* & Significant positive relationship \\
H9: $($ VL-IU) & Yes* & Significant negative relationship \\
H10: $($ PEOU-PU) & Yes* & Significant positive relationship \\
H11: $($ PEOU-IU) & Yes* & Significant positive relationship \\
H12: $($ PU-IU) & Yes* & Significant positive relationship \\
\hline
\end{tabular}

$* \mathrm{p}<0.001 ; * * \mathrm{p}<0.05$.

In Table 7, covariances between independent variables are examined in order to determine that the relationships between independent variables are significant or not. As it is presented in Table 7, defined covariances are significant in 0.001 level.

Table 7. Covariance significances

\begin{tabular}{ll}
\hline Covariance & \\
\hline PE - OQ & Yes* \\
PE - PEC & Yes* \\
PEC - OQ & Yes* \\
VL - EX & Yes* \\
OU - EX & Yes* \\
OU - VL & Yes* \\
PE - EX & Yes* \\
PE - VL & Yes* \\
PEC - EX & Yes* \\
PEC - VL & Yes* \\
JR - OQ & Yes* \\
JR - PE & Yes* \\
JR - PEC & Yes* \\
JR - CSE & Yes* \\
JR - EX & Yes* \\
JR - VL & Yes* \\
\hline
\end{tabular}

$* \mathrm{p}<0.001 ; * * \mathrm{p}<0.05$.

Another striking finding from the analysis; with regard to the variances of the construct; PU and PEOU explained $71 \%$ of the variance in IU while PU had the strongest affect. Additionally, 52\% of the variance in PU is explained by JR while PEC showed the strongest effect on PEOU. 


\section{Results}

Technology acceptance is one of the critical success factors for both practitioners and researchers. Fascinating development of technology with the effects of globalization lead every institution to improve and enhance their skills constantly. Along with the improvement attempts, companies perform all their tasks with electronic applications. Those applications create safe and accurate results for companies but it requires an impeccable technology transfer along with appropriate adaptation of technology. Thus, theoretical models of technology acceptance proposed and developed to make predictions about acceptance over the years. With the prediction results, companies have an ability to provide right service or backups for their employees to improve.

This study is aimed to propose a new research model for technology acceptance with multi criteria decision making approach to measure and explain users' acceptance of SAP software. In the study, original acceptance models are examined and variable selections are decided by decision makers with AHP method. According to the AHP results, variables are sorted in a descending order and Pareto analysis is applied to determine which variables will be included in research model and Experience, Voluntariness, Perceived Enjoyment, Perceptions of External Control, Computer Self Efficacy, Output Quality, Job Relevance are decided to create the TAM. To verify, measure and explain the users' acceptance of SAP software, new TAM is implemented with SEM. According to the results, job relevance, output quality, experience, voluntariness are in a significant relationship with perceived usefulness while perceptions of external control, computer self-efficacy are in a significant relationship with perceived ease of use. When TAM is analyzed with the perspective of perceived usefulness and perceived ease of use; $71 \%$ of the variance in intention to use is explained by these two constant variables which mean that perceived usefulness and perceived ease of use are the strong predictors for SAP users' intention to use.

The findings of the study have many theoretical and practical implications for companies that use SAP software. Results indicate that new TAM with the help of multi criteria decision making approach which is developed with the help of both previous studies and samples' decision makers to eliminate unnecessary calculations and hypotheses besides of being flexible, original and easily implemented.

Restricting and evaluating the data only from SAP users might be the limitation of the study. On the other hand results present that; new model is applicable for wider researches. Comparison of different type of users with the new AHP applications is considered for further studies.

\section{References}

Abdullah, F., \& Ward, R. (2016). Developing a General Extended Technology Acceptance Model for E-Learning (GETAMEL) by analysing commonly used external factors. Computers in Human Behavior, 56, 238-256. https://doi.org/10.1016/j.chb.2015.11.036

Alharbi, S., \& Drew, S. (2014). Using the Technology Acceptance Model in Understanding Academics' Behavioural Intention to Use Learning Management Systems. International Journal of Advanced Computer Science and Applications, 5(1), 143-155. https://doi.org/10.14569/IJACSA.2014.050120

Bagozzi, R. P., \& Yi, Y. (1988). On the evaluation of structural equation models. Journal of the academy of marketing science, 16(1), 74-94. https://doi.org/10.1007/BF02723327

Bentler, P. M., \& Bonett, D. G. (1980). Significance tests and goodness of fit in the analysis of covariance structures. Psychological bulletin, 88(3), 588. https://doi.org/10.1037/0033-2909.88.3.588

Brandon-Jones, A., \& Kauppi, K. (2018). Examining the antecedents of the technology acceptance model within e-procurement. International Journal of Operations \& Production Management, 38(1), 22-42. https://doi.org/10.1108/IJOPM-06-2015-0346

Briz-Ponce, L., \& Garcia-Penalvo, F. J. (2015). An Empirical Assessment of a Technology Acceptance Model for Apps in Medical Education. J Med Syst, 39(11), 176. https://doi.org/10.1007/s10916-015-0352-x

Davis, F. D. (1985). A technology acceptance model for empirically testing new end-user information systems: Theory and results. Massachusetts Institute of Technology.

Davis, F. D. (1989). Perceived usefulness, perceived ease of use, and user acceptance of information technology. MIS Quarterly, 319-340. https://doi.org/10.2307/249008

Davis, F. D., Bagozzi, R. P., \& Warshaw, P. R. (1989). User Acceptance Of Computer Technology: A Comparison Of Two Theoretical Models. Management Science, 35(8), 982-1003. https://doi.org/10.1287/ mnsc.35.8.982 
Fathema, N., Shannon, D., \& Ross, M. (2015). Expanding The Technology Acceptance Model (TAM) to Examine Faculty Use of Learning Management Systems (LMSs) In Higher Education Institutions. MERLOT Journal of Online Learning and Teaching, 11(2), 210-232.

Fishbein, M., \& Ajzen, I. (1975). Belief, attitude, intention and behavior: An introduction to theory and research.

Fornell, C., \& Larcker, D. F. (1981). Evaluating structural equation models with unobservable variables and measurement error. Journal of Marketing Research, 39-50. https://doi.org/10.2307/3151312

Heijden, H. v. d. (2004). User Acceptance of Hedonic Information Systems. MIS Quarterly, 28(4), 695-704. https://doi.org/10.2307/25148660

Jöreskog, K. G., \& Sörbom, D. (1996). PRELIS 2 user's reference guide: A program for multivariate data screening and data summarization: A preprocessor for LISREL: Scientific Software International.

Kim, H.-Y., Lee, J. Y., Mun, J. M., \& Johnson, K. K. P. (2016). Consumer adoption of smart in-store technology: assessing the predictive value of attitude versus beliefs in the technology acceptance model. International Journal of Fashion Design, Technology and Education, 10(1), 26-36. https://doi.org/10.1080/1754 3266.2016.1177737

Lala, G. (2014). The emergence and development of the technology acceptance model (TAM). Paper presented at the The Proceedings of the International Conference" Marketing-from Information to Decision".

Marakarkandy, B., Yajnik, N., \& Dasgupta, C. (2017). Enabling internet banking adoption. Journal of Enterprise Information Management, 30(2), 263-294. https://doi.org/10.1108/JEIM-10-2015-0094

Park, E., \& Kim, K. J. (2014). An Integrated Adoption Model of Mobile Cloud Services: Exploration of Key Determinants and Extension of Technology Acceptance Model. Telematics and Informatics, 31(3), 376-385. https://doi.org/10.1016/j.tele.2013.11.008

Park, S. Y. (2009). An Analysis of the Technology Acceptance Model in Understanding University Students' Behavioral Intention to Use e-Learning. Educational Technology \& Society, 12(3), 150-162.

Persico, D., Manca, S., \& Pozzi, F. (2014). Adapting the Technology Acceptance Model to evaluate the innovative potential of e-learning systems. Computers in Human Behavior, 30, 614-622. https://doi.org/ 10.1016/j.chb.2013.07.045

Rauniar, R., Chris, E., Professor Raymond H, D., Rawski, G., Yang, J., \& Johnson, B. (2014). Technology acceptance model (TAM) and social media usage: an empirical study on Facebook. Journal of Enterprise Information Management, 27(1), 6-30. https://doi.org/10.1108/JEIM-04-2012-0011

Rondan-Cataluña, F. J., Arenas-Gaitán, J., \& Ramírez-Correa, P. E. (2015). A comparison of the different versions of popular technology acceptance models. Kybernetes, 44(5), 788-805. https://doi.org/10.1108/ K-09-2014-0184

Saaty, T. L. (1980). The analytic hierarchy process: planning, priority setting, resources allocation. New York: McGraw, 281.

Saaty, T. L. (1989). Group decision making and the AHP The analytic hierarchy process (pp. 59-67): Springer. https://doi.org/10.1007/978-3-642-50244-6_4

Samaradiwakara, G. D. M. N., \& Gunawardena, C. G. (2014). Comparison Of Existing Technology Acceptance Theories And Models To Suggest A Well Improved Theory/Model. International Technical Sciences Journal, 1(1), 21-36.

Serçemeli, M., \& Kurnaz, E. (2016). Denetimde Bilgi Teknoloji Ürünleri Kullanımının Teknoloji Kabul Modeli (TKM) İle Araştırılması. Istanbul University Journal of the School of Business, 45(1), 43-52.

Shin, D.-H., \& Shin, Y.-J. (2011). Why do people play social network games? Computers in Human Behavior, 27(2), 852-861. https://doi.org/10.1016/j.chb.2010.11.010

To, W. M., \& Tang, M. N. F. (2018). Computer-based course evaluation: An extended technology acceptance model. Educational Studies, 1-14. https://doi.org/10.1080/03055698.2018.1443797

Venkatesh, V. (2000). Determinants of perceived ease of use: Integrating control, intrinsic motivation, and emotion into the technology acceptance model. Information systems research, 11(4), 342-365. https://doi.org/10.1287/isre.11.4.342.11872 
Venkatesh, V., \& Davis, F. D. (1996). A Model of the Antecedents of Perceived Ease of Use: Development and Test. Decision sciences, 27(3), 451-481. https://doi.org/10.1111/j.1540-5915.1996.tb01822.x

Venkatesh, V., \& Davis, F. D. (2000). A Theoretical Extension of the Technology Acceptance Model: Four Longitudinal Field Studies. Management Science, 46(2), 186-204. https://doi.org/10.1287/mnsc.46.2. 186.11926

Wallace, L. G., \& Sheetz, S. D. (2014). The adoption of software measures: A technology acceptance model (TAM) perspective. Information \& Management, 51(2), 249-259. https://doi.org/10.1016/j.im.2013.12.003

$\mathrm{Wu}$, J.-H., \& Wang, S.-C. (2005). What drives mobile commerce? Information \& Management, 42(5), 719-729. https://doi.org/10.1016/j.im.2004.07.001

\section{Copyrights}

Copyright for this article is retained by the author(s), with first publication rights granted to the journal.

This is an open-access article distributed under the terms and conditions of the Creative Commons Attribution license (http://creativecommons.org/licenses/by/4.0/). 